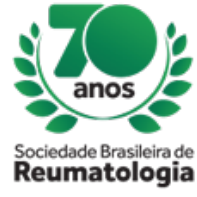

\title{
CLINICAL-EPIDEMIOLOGICAL PROFILE OF LEPER PATIENTS WITH OSTEOARTICULAR MANIFESTATIONS FOLLOWED UP IN OUTPATIENTS CLINICS OF TERTIARY HOSPITAL
}

Guilherme Escarião de Morais Nóbrega (UFPB, João Pessoa, PB, Brasil), Gabriel Dias Américo (UFPB, João Pessoa, PB, Brasil), Joanne Elizabeth Ferraz da Costa (UFPB, João Pessoa, PB, Brasil), Alessandra Sousa Braz (UFPB, João Pessoa, PB, Brasil)

\section{BACKGROUND}

Leprosy is a chronic, infectious and granulomatous disease, mainly compromising the skin. Among the extracutaneous regions, peripheral nerves and joints stand out. Such osteoarticular involvement may be of inflammatory or degenerative nature.

The study's objective was to draw a clinical-epidemiological profile of the leper patients with osteoarticular manifestations (OAM) from specific outpatients clinics of a tertiary hospital.

\section{MATERIALS AND METHODS}

The research was made involving leper patients with OAM. Out of 57 patients being followed up in the outpatients clinic, 35 participated of the study. Patients of both genders, with more than 18 years old, established diagnosis of leprosy and presence of OAM were included. Those in diagnostic investigation and those who did not agree in signing the free and informed consent were excluded. A questionnaire containing sociodemographic and leprosy-related information was applied: leprosy clinical form, classification, time of diagnosis, leprosy reaction (LR) occurrence and OAM emergence time. The last were evaluated by questions involving clinical manifestations (pain, edema, heat, redness, morning stiffness, difficulty to initiate movements and crepitations). Shoulders, elbows, wrists, kness and ankles were defined as large joints; proximal and distal interphalangeals, metacarpophalangeals and metatarsophalangeals as small joints.

\section{RESULTS}

: $58,82 \%$ of the participants were female and $41,18 \%$, male, with the majority between 35 and 60 years old $(66 \%)$. Regarding scholarity, $89 \%$ present from incomplete primary school to complete secondary school. $89 \%$ (31) of participants were classified as mutibacillary and $11 \%$, paucibacillary; the prevalent clinical form was the lepromatous, with $29 \%$ (10), followed by the borderline-lepromatous $(17 \% ; 6) ; 54 \%$ (19) were in LR, $47 \%$ (9) of those with type 1 LR, 32\% (6) type 2, and one patient with both types. $38 \%$ of the patients (8) with LR reported emergence during treatment, and the same percentage was verified to emergence after treatment. Regarding OAM, $97 \%$ (34) referred joint pain; $53 \%$ (18), edema; $11 \%$ (4), heat; one patient related redness. $40 \%$ (14) referred morning stiffness: $79 \%$ (11) of those, for less than 30 minutes; and $21 \%$ (24), more than 30 minutes. $43 \%$ (15) related difficulty to initiate movements, and crepitation (audible and/or palpable) was related in $20 \%$ (7).

\section{CONCLUSION}

The obtained data allow to affirm that the epidemiological profile of the participants is mostly characterized by women, between 35 and 60 years old, without university graduation. The clinical profile mainly includes mutibacillary patients, with the lepromatous clinical form, in LR (specially type 1 ) and with OAM initiated after diagnosis. 